УДК 616.379-008.64

\title{
СПЕЦИФИЧЕСКИЕ КОЖНЫЕ ПРОЯВЛЕНИЯ КАК МАРКЕР САХАРНОГО ДИАБЕТА И ПРЕДДИАБЕТИЧЕСКОГО СОСТОЯНИЯ
}

\author{
Юзбекова Аида Артуровна \\ Кухмазова Алина Теймуровна \\ студенты \\ Научный руководитель: Горелова Виктория Геннадьевна \\ к.М.Н., доцент \\ ФГБОУ ВО «Дагестанский \\ государственный медицинский университет»
}

Аннотация: Сахарный диабет (СД) - это заболевание, характеризующееся нарушением всех видов обмена веществ и расстройством жизнедеятельности организма. Это серьезное хроническое заболевание, распространенность которого растет во всем мире. Существует множество взаимосвязей между СД и рядом серьезных расстройств. Хотя основные осложнения этого состояния включают почки, сетчатку и периферические нервы, кожа пациентов с диабетом также травмируется. Поражения кожи часто наблюдаются у пациентов с СД в результате сложного взаимодействия биохимических, сосудистых, иммунных и метаболических изменений. Кожные проявления могут развиться в любое время в ходе СД. Они могут быть первым признаком заболевания, возможно, помогая в диагностике, или представлять собой маркер плохого контроля гликемии.

Ключевые слова: сахарный диабет, кожный маркер, дерматоз, инсулин, инсулинорезистентность, гипергликемия.

\section{SPECIFIC SKIN MANIFESTATIONS AS A MARKER OF DIABETES MELLITUS AND THE PREDIABETIC STATE}

\section{Yuzbekova Aida Arturovna Kukhmazova Alina Teimurovna}

\begin{abstract}
Diabetes mellitus (DM) is a disease characterized by a violation of all types of metabolism and a disorder of the vital activity of the body. This is a serious chronic disease, the prevalence of which is growing all over the world.
\end{abstract}


There are many correlations between DM and a number of serious disorders. Although the main complications of this condition include the kidneys, retina and peripheral nerves, the skin of diabetic patients is also injured. Skin lesions are often observed in patients with DM as a result of a complex interaction of biochemical, vascular, immune and metabolic changes. Skin manifestations can develop at any time during DM. They can be the first sign of the disease, possibly helping in diagnosis, or represent a marker of poor glycemic control.

Key words: diabetes mellitus, skin marker, dermatosis, insulin, insulin resistance, hyperglycemia.

Сахарный диабет (СД) - это гетерогенное состояние, характеризующееся гипергликемией, как следствие нарушений секреции инсулина и различной степени резистентности к инсулину. Кожные проявления наблюдаются как минимум у $30 \%$ диабетиков в течение их болезни, а некоторые могут даже появиться до подтверждения диагноза СД [1-4]. Быстрое распознавание этих часто недооцениваемых объектов чрезвычайно важно, поскольку это может привести не только к адекватной метаболической оценке, но и к своевременному надлежащему лечению, минимизации вторичных последствий долгосрочного диабета и улучшению прогноза пациентов с диабетом.

Они также могут представлять собой осложнения, возникающие у уже пролеченного пациента с диабетом. Некоторые из этих дерматозов (например, черный акантоз) являются маркерами макрососудистых осложнений. Те же самые расстройства и некоторые другие (например, ксероз) чаще ассоциируются с микроангиопатией при СД II типа.

Цель: оценить распространенность и основные клинические проявления кожных заболеваний у пациентов с СД. Детализировать различные части текущих знаний систематическим и кратким образом, так как это может помочь в определении молекулярных мишеней для профилактики и лечения повреждений кожи при СД и маркеров для мониторинга кожных и системных аспектов заболевания.

Диабетическая дермопатия - наиболее часто встречающееся кожное заболевание при сахарном диабете. Это кожное проявление впервые было зарегистрировано Хансом Мелином в 1964 году [5]. Мелин описал диабетическую дермопатию как небольшие, ограниченные, коричневатые, атрофические поражения кожи, которые обычно наблюдаются на нижних 
конечностях. Эти поражения протекают бессимптомно, не заразны и развиваются как единичные образования или кластеры и часто являются асимметричными и двусторонними. В своей оригинальной статье Мелин заявил, что эти поражения были более или менее специфичны для СД. Большинство опубликованных позже отчетов согласились с его выводами. Основной патогенез диабетической дермопатии неясен.

Ксероз - это второе по распространенности кожное проявление у людей с СД. В исследовании 100 пациентов с диабетом и поражениями кожи ксероз наблюдался у 44\% пациентов [6]. Наиболее распространенные признаки ксероза включают чрезмерно сухую, грубую, неровную и потрескавшуюся кожу.

К дерматозам, связанным с СД, относят и диабетическую склеродермию. Диабетическая склеродермия - это состояние толстых, уплотненных эритематозных бляшек, возникающих на верхней части спины и шеи. При поражениях может наблюдаться эритема. Это состояние наблюдается у 2,5-14\% людей с диабетом [7]. Дерматоз часто протекает бессимптомно, однако могут возникать боли в шее и спине. Диагноз обычно ставится клинически, хотя окончательный диагноз подтверждается биопсией кожи.

Считается, что патогенез диабетической склеродермии связан с повышенной стимуляцией инсулина и неферментативным гликозилированием коллагена. Это вызывает повышенное сшивание коллагена, делая коллагеновые волокна устойчивыми к разрушению коллагеназой и приводя к увеличению количества коллагена.

Связь с инсулинорезистентностью прослеживается и при черном акантозе (acantosis nigricans). Он представляет собой гиперпигментированное бархатистое утолщение кожных складок, проявляющееся преимущественно в области шеи, подмышечной впадины и паха. Возможные дополнительные проявления могут включать кожные метки и гиперкератоз [8]. Нигерийский акантоз, вероятно, является наиболее легко распознаваемым кожным проявлением диабета [9]. Он присутствует до 74\% взрослых пациентов с ожирением и может быть предиктором наличия гиперинсулинемии [10]. Наличие Нигерийского акантоза является прогностическим показателем развития сахарного диабета II типа. Центральную роль в развитии акантоза играет инсулин. У людей с сахарным диабетом II типа поджелудочная железа вырабатывает инсулин, но организм становится устойчивым к его 
воздействию, что приводит к недостаточному усвоению глюкозы и аномально повышенному уровню глюкозы в крови (гипергликемия) и моче. При состояниях инсулинорезистентности и гиперинсулинемии, акантоз может развиваться вследствие избыточного связывания инсулина к рецепторам ИФР - 1 на кератиноцитах и фибробластах. Связывание стимулирует пролиферацию кератиноцитов и фибробластов. Данные в пользу роли различных факторов роста в патогенезе черного акантоза продолжают накапливаться.

Ониходистрофия проявляется чрезмерным утолщением и деформацией ногтей, что может привести к накоплению инородных частиц и последующей инфекции пальца ноги, которую следует лечить как диабетическую язву. Плохо сидящая обувь может привести к повторной травме и ухудшению состояния поврежденного места [11]. У пациентов с диабетом ониходистрофия является результатом плохого периферического кровообращения и диабетической невропатии. Само это состояние может вызвать язвы диабетической стопы [12].

Недиагностированный сахарный диабет и гипертриглицеридемия могут провоцировать появление на коже эруптивных ксантом. Эруптивная ксантома (ЭКС) представлена на ягодицах, локтях и коленях в виде внезапно появившихся желтых папул с эритематозной основой $[2,13]$. ЭКС встречается редко и чаще встречается у пациентов с плохо контролируемым диабетом II типа. Эти поражения могут быть первым признаком диабета. Снижение активности липопротеинлипазы, наблюдаемое при инсулинозависимом диабете, приводит к накоплению триглицеридов в сыворотке крови. Иногда, когда уровень триглицеридов в сыворотке крови достигает 2000 мг/дл, липиды откладываются в коже [13].

Акрохордоны, или фиброэпителиальные полипы, кожные метки и мягкие фибромы, представляют собой плодоножечные выросты нормальной кожи на узком стебле, чаще всего расположенные на веках, шее, подмышечных впадинах и паху. Связь между гиперинсулинемией и кожными метками была хорошо установлена [14].

К заболеваниям, которые связаны с сахарным диабетом и имеют неясный патогенез, относят диабетический буллез, анулярную гранулему, липоидный некробиоз.

Буллезный дерматоз, или диабетические булль,, наблюдается у 0,5\% людей, страдающих сахарным диабетом. Это состояние чаще наблюдается у 
мужчин и у лиц с давней периферической невропатией. Поражения возникают спонтанно и в основном по бокам голеней и стоп. Иногда они видны на предплечьях и кистях рук. Повреждения представлены в виде прозрачной буллы на невоспаленных основаниях, которые безболезненны и содержат стерильную жидкость. Размер поражения может варьироваться от нескольких миллиметров до нескольких сантиметров [15]. Патология волдырей в настоящее время неизвестна.

Анулярная гранулема представляет собой эритематозные папулы телесного цвета, сливающиеся в овальное или кольцевое поражение. Она часто протекает бессимптомно, но может вызывать зуд или ощущение жжения. [16].

Липоидный некробиоз, или болезнь Оппенгейма-Урбаха, встречается редко, у 0,3-1,6\% людей с диабетом I типа, чаще у женщин, чем у мужчин [17, 18]. Типичные поражения наблюдаются у пациентов молодого и среднего возраста. Болезнь Оппенгейма-Урбаха имеет весьма многообразную клиническую картину и чаще всего проявляется в виде неправильных, безболезненных яйцевидных бляшек с желтым атрофическим центром и красно-фиолетовой периферией. Часто можно обнаружить телеангиоэктазии, придающие областям поражения блеск «глазурованного фарфора». В процесс вовлекаются различные участки кожного покрова, преимущественно кожа передней поверхности голеней. Это объясняется тем, что при диабете патологические изменения первоначально происходят в мелких сосудах нижних конечностей.

Некоторые кожные заболевания вызваны или могут быть вызваны системными нарушениями, и эти знания имеют большое значение для врача общей практики. По мере роста заболеваемости сахарным диабетом кожные проявления, связанные с ним, будут становиться все более распространенными. Распознавание кожных маркеров позволит проводить более раннее выявление недиагностированного СД. Таким образом, представленные сигнатуры кожи должны привести к диагностической оценке, ориентированной на сахарный диабет. 


\section{Список литературы}

1. Браверман ИМ. Кожные проявления сахарного диабета. Мед Клин. Северная Америка, 1971; 55: 1019-29.

2. Парон Н.Г., Ламберт П.В. Кожные проявления сахарного диабета. Prim Care 2000;27:371-83.

3. Хантли AC. Кожные проявления сахарного диабета J Am Acad Дерматол 1982;7:427-55.

4. Аллен Г.Э. Сахарный диабет и кожа. Практика 1969; 203:189-93

5. Мелин Х. Атрофическое очерченное поражение кожи нижних конечностей у диабетиков. Acta Med Scand. 1964;176(Дополнение 423):9-75.

6. Гоял А, Райна С, Каушал С. С., Махаджан В, Шарма НЛ. Характер кожных проявлений при сахарном диабете. Индийский J Dermatol 2010;55: $39-41$

7. Коул Г. В., Хедли Дж., Скоуски Р. Диабетическая склеродема: распространенное и отчетливое кожное проявление сахарного диабета. Лечение диабета 1983;6:189-1922.

8. Конг А.С., Уильямс Р.Л., Смит М., Сассман А.Л., Шкипер Б., Хси А.С., Райн Р.Л. Черный акантоз и факторы риска диабета: распространенность среди молодежи, наблюдаемая в практике первичной медико-санитарной помощи на юго-западе США. Анналы семейной медицины. - 2007; 5(3): 202-208.

9. Калус АА, Чиен Эй Джей, Олеруд ДЖЕ. Глава 151: Сахарный диабет и другие эндокринные заболевания. В дерматологии Фитцпатрика в общей медицине. 8-е изд.Голдсмит ЛА, Кац СИ, Гилкрест БА, Паллер АС, Леффелл диджей, Вольф К, Ред. Нью-Йорк, Макгроу-Хилл, 2012; Доступно онлайн с http://accessmedicine. mhmedical.com/content.aspx ?bookid=392\&sectionid=41138 874.

10. Худ Джа-младший, Коэн Дж. Б., Вагнер Дж. М., Круз П. Д.младший. Распространенность и значение нигерийского акантоза у взрослого населения с ожирением. Архидерматол 1992;128:941-944.

11. Mutluoglu M, Uzun G, Karabacak E. Ониходистрофия ногтей на ногах при диабетической стопе.

12. Милликен ЛЕ, Пауэлл Д. У., Дрейк Л. А. Качество жизни пациентов с онихомикозом. Int J Дерматол 1999;38(доп. 2):13-16

13. Martínez DP, Díaz JÓF, Bobes CM. Эруптивные ксантомы и острый панкреатит у пациента с гипертриглицеридемией. Int Arch Med 2008;1:6. 
14. Кахана М, Гроссман Е, Файнштейн А, Роннен М, Коэн М, Миллет M. Кожные метки: кожный маркер сахарного диабета. Acta DermatoVenereologica 1987;67:175-177

15. Пальцик Р.Л. Буллезная сыпь при сахарном диабете. Буллез диабетический. Архивы дерматологии. - 1980; 116: 475-476.

16. Сахин М. Т., Тюрель-Эрмерткан А, Озтюркан С, Тюркдоган П. Генерализованная гранулема у пациента с сахарным диабетом II типа: успешное лечение изотретиноином.

17. Кота СК, Джаммула С, Кота СК, Мехер ЛК, Моди КД. Некробиоз липоидный диабетический: обзор литературы на основе конкретных случаев. Индийский Ј Эндокринол Метаб 2012;16:614-620

18. Ферринджер T, Миллер Ф 3-й. Кожные проявления сахарного диабета. Клиника Дерматола 2002;20:483-492.

(C) А.А. Юзбекова, А.Т. Кухмазова, 2022 